\title{
Influence of diet on the metabolic responses to exercise
}

\author{
Lawrence L. Spriet* and Sandra J. Peters \\ Department of Human Biology and Nutritional Sciences, University of Guelph, Guelph, Ontario NIG 2Wl, Canada
}

Exercise requires the skeletal muscles of the body to convert large amounts of chemical energy into mechanical energy. The chemical energy is provided through the dietary intake of food, which is metabolized by the muscles to produce ATP, the currency required to produce mechanical energy. Consequently, the relationship between dietary intake and skeletal-muscle exercise metabolism is an obvious one and has been examined experimentally for over 100 years. However, while the effects of highcarbohydrate (CHO)-low-fat diets and low-CHO high-fat diets on substrate metabolism during exercise have been described, very little is known regarding the mechanisms that induce these changes over the short or long term.

The present paper will provide a brief historical overview of the classic studies examining the importance of diet and specifically dietary $\mathrm{CHO}$ for maximizing metabolic energy production during exercise. It will also compare more recent studies that examined the effects of highCHO-low-fat and low-CHO-high-fat diets lasting days and weeks on: (1) the activities of key enzymes of the energyproducing pathways, (2) the $\mathrm{CHO}$ and fat stores in skeletal muscle, (3) the metabolic responses to exercise and the mechanisms that may regulate the diet-induced alterations. The emphasis in the present paper is on whole-body and skeletal-muscle $\mathrm{CHO}$ and fat metabolism in exercising human subjects, although data from other mammals are cited where necessary. The effects of diet on protein metabolism and exercise performance and the effects of acute feedings on exercise metabolism and performance will not be reviewed here. Many aspects of the relationship between diet and the metabolic responses to exercise have been previously reviewed (Hultman \& Spriet, 1988; Sherman et al. 1991; Coggan \& Mendenhall, 1992; Coyle, 1997). The reader is referred to these reviews and other papers in the present symposium for the topics that are not covered in the present review.

\section{Historical introduction}

In the late 1800s Zuntz and colleagues reported that both fat and $\mathrm{CHO}$ were combusted during exercise that was not too intense and could be performed for a long time (for review, see Asmussen, 1971). At the same time, Chavreau and colleagues argued that CHO was the only energy source during intense exercise that exhausted subjects in about $1 \mathrm{~h}$ (Asmussen, 1971). Pettenhaufer and Voit had already demonstrated, using urinary $\mathrm{N}$ output measurements, that protein was not a major fuel for exercise in healthy well-fed men (Asmussen, 1971). These investigators based their conclusions on measurements of the respiratory exchange ratio (RER; $\mathrm{CO}_{2}$ output: $\mathrm{O}_{2}$ uptake measured at the mouth) and the knowledge that oxidation of $\mathrm{CHO}$ and fat gave RER values of 1.0 and 0.7 respectively. As summarized by Asmussen (1971), later studies from three laboratories, in which the amounts of dietary fat and $\mathrm{CHO}$ were manipulated, demonstrated that both fat and $\mathrm{CHO}$ were oxidized during exercise. The relative amounts of fat and $\mathrm{CHO}$ oxidized during low- and moderate-intensity exercise depended on the diet, and the contribution from fat increased as exercise was prolonged. Exercise performance also decreased with a preceding high-fat diet and increased following a high-CHO diet. The contribution of energy from $\mathrm{CHO}$ increased as the exercise intensity increased above the moderate range, reaching approximately $100 \%$ at maximal intensities.

Classic studies: 1963-1971

Direct measurements of fuel stores and utilization during exercise

The early estimations of fat and CHO oxidation in skeletal muscle during exercise were indirect (from ventilatory RER measurements) and gave no information regarding the source of the fuel. As more sophisticated and invasive techniques became available in the 1960 s, researchers were able to determine the locations and importance of the various fuel stores in the body. The major sources of fat during exercise were long-chain non-esterified fatty acids (NEFA), released from adipose-tissue triacylglycerol (TAG) and delivered to the muscles, and from NEFA released from TAG stored directly in the muscles. Similarly, CHO was transported to the muscles in the form of glucose derived from stored liver glycogen and the de novo synthesis of glucose in liver, and also provided from

\footnotetext{
Abbreviations: $\mathrm{CHO}$, carbohydrate; CoASH, free CoA; CS, citrate synthase; G-6-P, glucose-6-phosphate; $\beta$-HAD, $\beta$-hydroxyacyl-CoA dehydrogenase; HCD, high-CHO-low-fat diet; LCD, low-CHO-high-fat diet; NEFA, non-esterified fatty acids; PDH, pyruvate dehydrogenase; RER, respiratory exchange ratio; TAG, triacylglycerol; $\mathrm{TAG}_{\mathrm{m}}$, intramuscular TAG; TCA, tricarboxylic acid; $V_{\mathrm{O}_{2} \max ,}$ maximum $\mathrm{O}_{2}$ uptake. *Corresponding author: Dr L. Spriet, fax +1 519763 5902, email L.SPRIET.NS@APS.UoGuelph.CA
} 
significant stores of glycogen in the muscle. The importance of exogenous glucose and NEFA as fuels during exercise has been summarized in previous reviews on diet and exercise energy metabolism (Hultman \& Spriet, 1988; Coggan \& Mendenhall, 1992).

The most significant contribution towards clarifying the importance of dietary $\mathrm{CHO}$ and skeletal-muscle glycogen for exercise was provided by Hultman \& Bergstrom (1967), who re-introduced the needle-biopsy procedure for extracting small amounts of tissue from human skeletal muscle and liver and pioneered the analytical techniques to measure tissue $\mathrm{CHO}$ content.

In the first study to examine human skeletal-muscle glycogen utilization during exercise, untrained subjects cycled to exhaustion at approximately $80 \%$ of their maximum $\mathrm{O}_{2}$ uptake $\left(V_{\mathrm{O}_{2} \max }\right)$ using a work : rest ratio of 15 min cycling : 15 min rest (Bergstrom \& Hultman, 1967). The rate of glycogen utilization in the vastus lateralis muscle was greatest in the initial $15 \mathrm{~min}$ and decreased successively with each additional $15 \mathrm{~min}$ period (Fig. 1). At exhaustion, muscle glycogen stores were essentially depleted. Additional work demonstrated that when cycling was sustained for as long as possible at various power outputs, muscle glycogen utilization increased in an approximately exponential manner (Saltin \& Karlsson, 1971; Fig. 2). Glycogen utilization rates at power outputs corresponding to 50,100 and $150 \% V_{\mathrm{O}_{2} \max }$ were $0.7,3.4$ and $10.0 \mathrm{mmol}$ glucosyl units $/ \mathrm{kg}$ wet weight per min. Similar rates were obtained from biopsies from a variety of muscles during other forms of exercise (Hultman \& Spriet, 1988; Fig. 2). At power outputs below $50 \% V_{\mathrm{O}_{2} \max }$, muscle and blood CHO contributed less than half the fuel, but muscle glycogen became the dominant fuel at power outputs above $50 \% V_{\mathrm{O}_{2} \max }$ (Saltin \& Karlsson, 1971). The

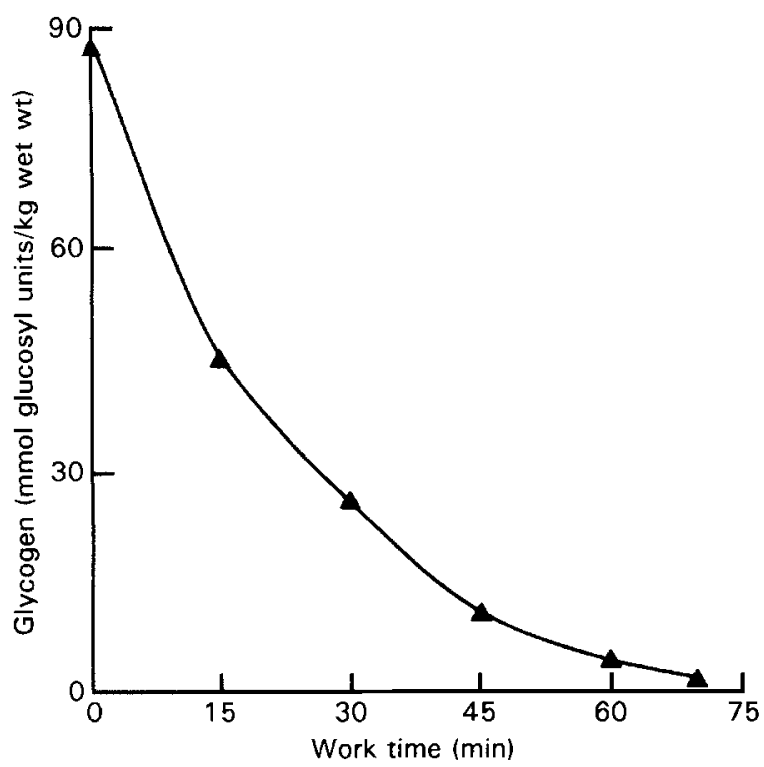

Fig. 1. Glycogen content in the vastus lateralis muscle as a function of cycling time at $80 \%$ maximum oxygen uptake. Data points are the mean values determined using ten subjects. For each subject, exercise was performed repeatedly in periods of $15 \mathrm{~min}$ separated by 15 min rest periods. (Data from Bergstrom \& Hultman, 1967.)

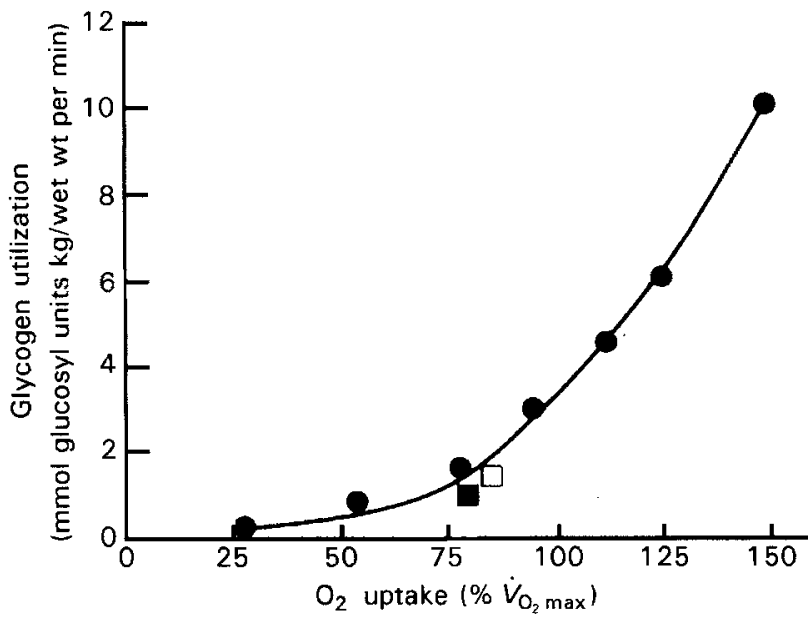

Fig. 2. Muscle glycogen utilization rates at various work intensities during different types of exercise. (-), Cycling, vastus lateralis muscle; $(\square)$, running, soleus muscle; $(\square)$, running, gastrocnemius muscle. $V_{O}$ max, maximum oxygen uptake. (Figure redrawn from Hultman \& Spriet, 1988.)

ability to cycle to exhaustion at power outputs between 65 and $85 \% V_{\mathrm{O}_{2} \max }$ coincided with depletion of the muscle glycogen store. At power outputs above approximately $75 \% V_{\mathrm{O}_{2} \max }$, muscles were unable to substitute fat for $\mathrm{CHO}$ even when the glycogen stores were depleted. Aerobic training increased the reliance on fat as fuel and decreased the use of $\mathrm{CHO}$, particularly muscle glycogen, up to power outputs of $80-85 \% V_{\mathrm{O}_{2} \max }$ (see Holloszy \& Coyle, 1984).

Skeletal-muscle biopsy samples also demonstrated that substantial amounts of intramuscular TAG $\left(\mathrm{TAG}_{\mathrm{m}}\right)$ were used during prolonged exercise (Froberg et al. 1971). Unfortunately, it is now known that the distribution of fat in muscle is not homogeneous and relatively large amounts of $\mathrm{TAG}_{\mathrm{m}}$ must undergo lipolysis in order to accurately detect changes during exercise using the biopsy technique (Frayn \& Maycock, 1980; Wendling et al. 1996). Consequently, it is common to estimate $\mathrm{TAG}_{\mathrm{m}}$ use from measurements of exogenous NEFA and total fat oxidation (from RER) and an assumed exercising muscle mass, as was classically reported by Havel et al. (1967) with untrained subjects and recently in trained subjects by Romijn et al. (1993).

\section{The influence of diet on carbohydrate metabolism in muscle and liver}

Due to the importance of $\mathrm{CHO}$ and specifically muscle glycogen during exercise, much of the early experimental dietary work examined the relationships between $\mathrm{CHO}$ intake, muscle glycogen content and exercise performance. It became clear that feeding a CHO-rich diet, a CHO-poor diet (high fat and protein) or even total starvation for 5-7d did not affect muscle glycogen content by more than approximately $30 \%$ when subjects refrained from exercise (Hultman, 1967; Hultman \& Bergstrom, 1967). However, when subjects engaged in exercise that depleted the muscle glycogen store and were then subjected to different diets in the recovery period, the results were striking (Hultman, 
1967). Total starvation for $1 \mathrm{~d}$, or a CHO-poor diet for 5-6 d following exercise resulted in very low rates of glycogen resynthesis $(<20 \mathrm{mmol} / \mathrm{kg}$ per $\mathrm{d})$. When a CHO-rich diet was given at any point in the period following exercise, the glycogen store was rapidly replenished (approximately 70 $75 \mathrm{mmol} / \mathrm{kg}$ per d) to amounts in excess of the pre-exercise levels. A series of experiments with a one-leg exercise model (Bergstrom \& Hultman, 1966) demonstrated several important points when one leg was exercised to deplete muscle glycogen while the other leg rested: (1) a CHO-rich diet increased muscle glycogen to levels approximately 2 -fold higher than pre-exercise levels, (2) a CHO-poor diet did not allow glycogen resynthesis in the exercised leg, (3) the dietary manipulations had little effect on the rested leg since the glycogen supercompensation was confined to the exercised muscles (Fig. 3). The study that linked the importance of dietary $\mathrm{CHO}$ intake and skeletal-muscle glycogen content to optimal exercise performance was performed by Bergstrom et al. (1967). Subjects cycled to exhaustion at $75 \% \quad V_{\mathrm{O}_{2} \max }$ on three occasions, each separated by $3 \mathrm{~d}$ and following different, but normal-energy diets. A mixed diet was given before the first ride, a $\mathrm{CHO}$ poor diet before the second ride and a $\mathrm{CHO}$-rich diet before the final ride. The mixed, $\mathrm{CHO}$-poor and $\mathrm{CHO}$-rich diets produced pre-exercise glycogen contents of 118,42 and $227 \mathrm{mmol} / \mathrm{kg}$ wet weight respectively and a strong correlation existed between the pre-exercise glycogen content and cycling time to exhaustion (Fig. 4). Exhaustion coincided with glycogen depletion regardless of the preceding diet. A field study later demonstrated that these laboratory results were applicable to race situations, as a high-CHO diet increased pre-race glycogen content and decreased $30 \mathrm{~km}$ running time as compared with a mixed diet (Karlsson \& Saltin, 1971). These dietary and exercise manipulations to increase muscle glycogen content were quickly adapted by athletes to 'glycogen supercompensate' or 'glycogen load' muscles and optimize performance during exercise. Later studies reported alternative dietary and exercise combinations that were easier to incorporate into training schedules and equally effective in increasing muscle glycogen content (Sherman et al. 1991).

The liver also plays a large role in CHO metabolism during exercise as it must increase the release of glucose to meet the increased demands of the working skeletal muscles and at the same time maintain a relatively constant blood glucose concentration to ensure central nervous system integrity.

In a series of remarkable studies in the 1970s, Hultman \& Nilsson (1971) made direct measurements of liver glycogen stores and provided a substantial amount of information regarding diet, liver $\mathrm{CHO}$ metabolism and exercise. Liver glycogen content was extremely labile when $\mathrm{CHO}$ intake was restricted, even in the resting state. Even $1 \mathrm{~d}$ without $\mathrm{CHO}$ in the diet was enough to deplete the liver glycogen store. When exercise was performed following a CHO-poor diet, glucose output from liver

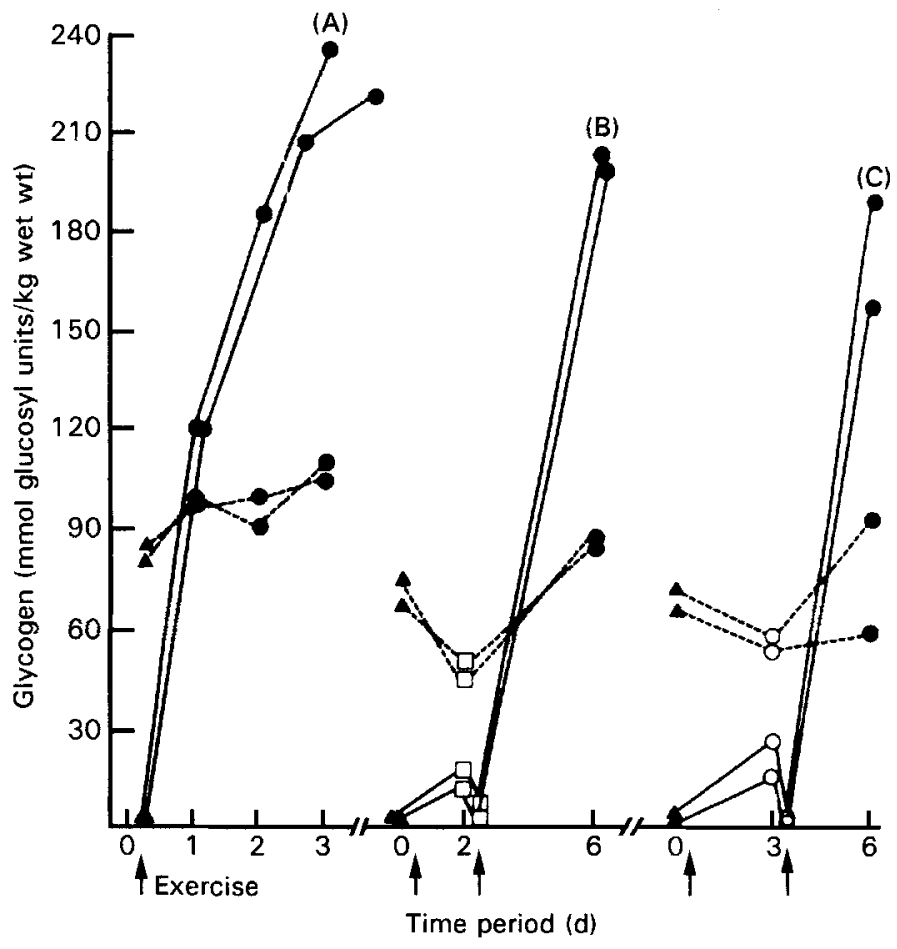

Fig. 3. One-leg exercise studies showing the muscle glycogen content of the exercised (-) and rested (-..--) legs. (A) Biopsy specimens were obtained immediately after the exercise $(\boldsymbol{A})$ and during $3 d$ when subjects were fed on a carbohydrate (CHO)-rich diet (O). (B, C) The diet was total starvation ( $\square$ ) for $2 \mathrm{~d}$ following exercise $(\mathrm{B})$ or $\mathrm{CHO}$-poor $(\mathrm{O})$ for $3 \mathrm{~d}$ following exercise $(\mathrm{C})$; this was followed by a second one-leg exercise bout $(\uparrow)$ and a CHO-rich diet (๑). (Data from Hultman, 1967.) 


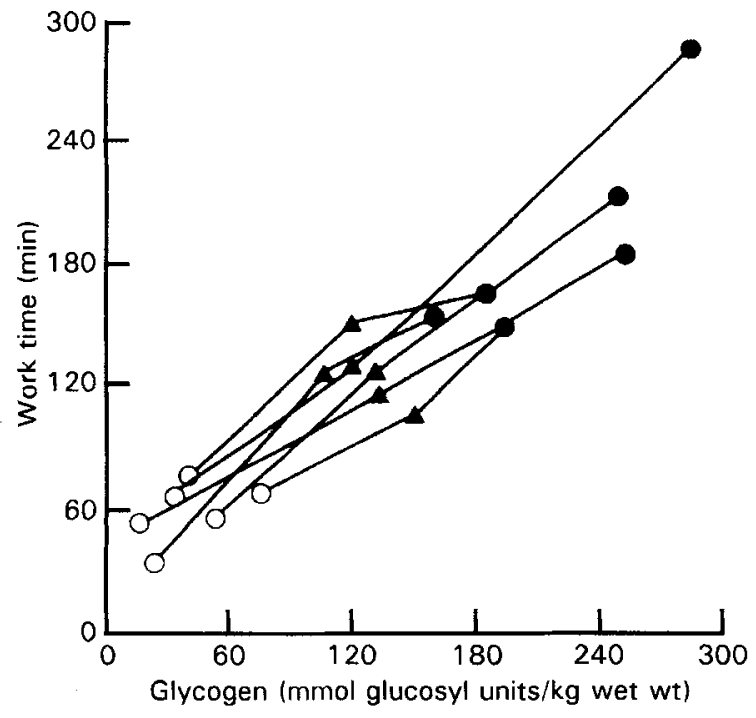

Fig. 4. The relationship between the initial glycogen content in vastus lateralis muscle and work time. Six subjects cycled to exhaustion at a work load corresponding to $75 \%$ of maximum oxygen uptake. Each subject worked three times. The first experiment was preceded by a mixed diet $(\mathbf{A})$, the second by a carbohydrate $(\mathrm{CHO})$-poor diet $(\mathrm{O})$, and the third by a $\mathrm{CHO}$-rich diet (O). The energy contents of the diets were identical. (Data from Bergstrom \& Hultman, 1967.)

glycogen was severely reduced and increased gluconeogenesis could not make up the difference. Mean blood glucose concentrations decreased from 5.0 to $2.8 \mathrm{mmol} / 1$ after $1 \mathrm{~h}$ of exercise and some subjects stopped cycling due to central nervous system dysfunction. Liver glucose output was much higher following a CHO-rich diet and blood glucose concentrations were maintained for almost $3 \mathrm{~h}$. These results demonstrated the importance of maximizing liver glycogen stores through daily $\mathrm{CHO}$ intake. This is especially true when exercise is performed in the morning following an overnight fast.

\section{Diet and metabolic adaptations: contemporary studies}

The effects of extremes of diet, either a low-CHO high-fat (and high-protein) diet or a high-CHO low-fat (and lowprotein) diet on the activities of key enzymes of the energyproducing pathways, the $\mathrm{CHO}$ and fat stores in skeletal muscle, and the metabolic responses to exercise and the mechanisms that may regulate the diet-induced alterations will now be examined. Recent research focuses on dietaryinduced metabolic adaptations and responses to exercise other than muscle glycogen, as this has already been well documented.

\section{Enzyme-protein adaptations}

It is common to assess the adaptation to a stressor by measuring the maximal activities of key enzymes in the pathways that are central to the production of ATP during exercise. These would include enzymes in the glycogenolytic and glycolytic pathways, the tricarboxylic acid (TCA) cycle, the $\beta$-oxidation pathway, the respiratory chain and selected other key enzymes such as pyruvate dehydrogenase complex (EC 1.2.4.1 +EC 1.8.1.4 +EC 2.3.1.12); $\mathrm{PDH}$ ) and carnitine palmitoyltransferase I (EC 2.3.1.21). The enzymes selected for study would normally be non-equilibrium regulatory enzymes, although in pathways believed to be equilibrium in nature, any enzyme could be measured.

Kiens et al. (1987) did not report changes in the maximal activities of the oxidative enzymes citrate synthase (EC 4.1.3.7; CS) and $\beta$-hydroxyacyl-CoA dehydrogenase (EC 1.1.1.35; $\beta$-HAD) after 4 weeks on a modestly-increased fat diet in human subjects (control fat intake, $43 \%$ of total energy intake $v$. fat diet, $54 \%$ of total energy intake). However, $\beta$-HAD activity increased by $120 \%$ following 7 weeks during which the dietary fat was increased to approximately $60 \%$ total energy compared with a $37 \%$ total energy control (Helge \& Kiens, 1997). No change in CS activity occurred. This recent finding for $\beta$-HAD activity in human studies agrees with results of rat studies using diets with extreme increases in dietary fat content $(60-70 \%$ total energy as fat), which showed marked increases in skeletal-muscle $\beta$-HAD activities. However, results of many of the rat studies also showed increases in CS activity of approximately $20 \%$ (Miller et al. 1984; Simi et al. 1991; Lapachet et al. 1996), with the largest increases demonstrated in type IIb fibres (Nemeth et al. 1992). The increased $\beta$-HAD and CS activities suggest that adaptation to a very-high-fat diet increased oxidative potential. This is supported by evidence from dog skeletal muscle that showed markedly increased mitochondrial volume (20$40 \%$, using histological techniques) with prolonged adaptation (4-6 weeks) to a high-fat diet (65\% total energy v. $25 \%$ total energy as fat in control; Taylor et al. 1994). Simi et al. (1991) also demonstrated a $13 \%$ increase in $V_{\mathrm{O}_{2} \max }$ following adaptation to a high-fat diet in rats. However, similar to the findings of the human studies, other rat studies have reported no increases in oxidative potential or maximal CS activity (Orfali et al. 1993; Bryson et al. 1995; Fryer et al. 1995).

PDH activity regulates the entry of $\mathrm{CHO}$ into the TCA cycle, and although maximal activities of the total complex do not change with diet, there were measurable decreases in the active form (PDHa) following $3 \mathrm{~d}$ on a low-CHO-highfat diet in human subjects (Putman et al. 1993) and in rats following $28 \mathrm{~d}$ on a diet containing $45-59 \%$ total energy as fat (Bryson et al. 1995; Fryer et al. 1995). This was accompanied by an increase in PDH kinase (EC 2.7.1.99) activity in rats (Fryer et al. 1995). However, the composition of the fat in the diet was important, as substitution with $n-3$ fatty acids (equally for saturated (mainly stearic) and monounsaturated (mainly oleic) fatty acids) eliminated this effect (Fryer et al. 1995).

The maximal activities of the glycolytic enzymes hexokinase ( $E C$ 2.7.1.1), glyceraldehyde-3-phosphate dehydrogenase $(E C$ 1.2.1.12) and lactate dehydrogenase $(E C$ 1.1.1.27) in human skeletal muscle did not change on a high-fat diet (Kiens et al. 1987; Helge \& Kiens, 1997). The activities of the enzymes phosphofructokinase (EC 2.7.1.11), hexokinase and lactate dehydrogenase were also generally unaffected by a high-fat diet in rat skeletal muscle (Simi et al. 1991; Zierath et al. 1997), although 
phosphofructokinase activity decreased in one study (Nemeth et al. 1992). Although insulin resistance is a well-documented response to a high-fat diet, the content of the insulin-regulatable glucose transporter (GLUT4) did not decrease in rat skeletal muscle (Zierath et al. 1997). Instead, the reduction in insulin-stimulated glucose uptake appeared to be due to decreased translocation of the transporter to the plasma membrane (Zierath et al. 1997). However, there was no change in contraction-mediated GLUT4 translocation or glucose uptake with a high-fat diet (Liu et al. 1996; Zierath et al. 1997). One would predict, therefore, a decrease in muscle glucose uptake at rest and no change during exercise in rat skeletal muscle adapted to a high-fat diet.

\section{Diet and the storage of intramuscular fuels}

As previously discussed, early studies with male subjects showed decreased muscle glycogen storage with $\mathrm{CHO}$ restriction through fasting or a high-fat diet when exercise was continued, but well-conserved muscle glycogen contents in the absence of physical activity (Hultman, 1967; Hultman \& Bergstrom, 1967). Both points were supported by recent human studies (Kiens et al. 1987; Putman et al. 1993). Cutler et al. (1995) examined human skeletal-muscle glycogen synthase ( $E C$ 2.4.1.11) and observed an increase in insulin sensitivity following 3 weeks on a low-CHO - high-fat diet (\% dietary energy; 8 $\mathrm{CHO}, 75 \mathrm{fat})$. This increase in glycogen synthase sensitivity to insulin correlated well with the $V_{\mathrm{O}_{2} \max }$ of the subject, leading to the conclusion that there was an interaction between physical conditioning and dietary $\mathrm{CHO}$ availability. Two recent studies demonstrated an inability of well-trained female subjects to glycogen supercompensate following an exercise and high-CHO-diet (70-75\% total energy as $\mathrm{CHO}, 3-4 \mathrm{~d}$ ) regimen as compared with a mixed-diet (51-57\% total energy as CHO) control (Tarnopolsky et al. 1995; Walker et al. 1996). It is currently not known why well-trained females do not store muscle glycogen to the same extent as well-trained males.

Kiens et al. (1987) observed an increased deposition of $\mathrm{TAG}_{\mathrm{m}}$ with a modest increase in dietary fat, possibly facilitated by a coordinated increase in skeletal muscle lipoprotein lipase (EC 3.1.1.34) activity. This finding is in agreement with the increased $\mathrm{TAG}_{\mathrm{m}}$ content following high-fat adaptation in many rat studies (Conlee et al. 1990; Bryson et al. 1995; Lapachet et al. 1996; Oscai \& Esser, 1996). One study also demonstrated that the magnitude of the $\mathrm{TAG}_{\mathrm{m}}$ deposition was proportional to the fat content of the diet (Oscai \& Esser, 1996).

\section{Diet, fuel selection (RER) and hormonal changes during exercise}

There is a paucity of information regarding the effects of a low-CHO-high-fat diet on skeletal-muscle metabolism during exercise in human subjects. Most investigations do not study skeletal-muscle metabolism directly, but rely on pulmonary and plasma measurements to represent changes.
Evidence from pulmonary RER measurements indicates that with CHO deprivation (and high fat) there is a fuel shift towards less reliance on $\mathrm{CHO}$ and more on fat both at rest and during exercise. Jansson et al. (1982) observed a significant reduction in RER in resting subjects $(0.71 \mathrm{v}$. 0.87 ) after $5 \mathrm{~d}$ on a diet consisting of $72 \%$ energy as fat. Even with a less-extreme diet $(52 \%$ energy as fat $v .38 \%$ energy as fat, control), modest but significant differences $(0.82 v, 0.90)$ have been documented using a more sensitive $24 \mathrm{~h}$ measurement (Thomas et al. 1992). Many studies have demonstrated significant changes in RER with varying exercise intensities and durations, and dietary conditions (Jansson et al. 1982; Putman et al. 1993; Helge et al. 1996).

In two studies subjects trained concurrently with the dietary manipulations. Helge et al. (1996) compared trained subjects on a modestly-elevated-fat diet ( 7 weeks, $\%$ total energy; 61 fat, $24 \mathrm{CHO}$ ) with trained subjects on a control diet (\% total energy; 21 fat, $65 \mathrm{CHO}$ ) and found lower RER at all time points $(0.82 v .0 .87)$ during exercise at $81 \%$ $V_{\mathrm{O}_{2} \max }$. Phinney et al. (1982) used an extremely-high-fat diet ( $85 \%$ total energy as fat) and training for 4 weeks compared with a control diet (67\% total energy as $\mathrm{CHO}$ ) and training, and observed a more marked difference $(0.72$ v. 0.83 ) during exercise at $63 \% V_{\mathrm{O}_{2} \max }$.

With increased fat catabolism, there is a marked increase in circulating ketone bodies (plasma $\beta$-hydroxybutyrate), provided that the dietary alteration is severe enough (Phinney et al. 1982; Kiens et al. 1987). The increasing reliance on fat as the fuel of choice during dietary CHO restriction is in part due to the decreased availability of intramuscular glycogen stores and increased $\mathrm{TAG}_{\mathrm{m}}$ deposition, as discussed previously. Increased $\mathrm{TAG}_{\mathrm{m}}$ utilization has been demonstrated in human subjects following $5 \mathrm{~d}$ on a low-CHO-high-fat diet, along with increased NEFA uptake and decreased glycogen utilization (Jansson, 1980). Resting insulin levels were lower after a fat-enriched diet, possibly as a secondary response to the reduced rate of plasma glucose appearance (Jansson et al. 1982; Johannessen et al. 1982). During exercise after a high-fat diet, insulin levels are consistently lower at all time points and decrease in parallel with control levels with time. In addition, resting insulin-stimulated glucose uptake is impaired with high fat consumption, although it appears that exercise-mediated glucose uptake is unaffected by diet in human (Putman et al. 1993; Cutler et al. 1995) and rat skeletal muscle (Liu et al. 1996). This is in good agreement with the molecular signalling adaptations to a high-fat diet discussed previously (Zierath et al. 1997).

The adrenaline and nonadrenaline responses to exercise are augmented after a high-fat diet and could contribute to increased NEFA mobilization from adipose TAG, elevated plasma NEFA levels and increased skeletal muscle NEFA uptake and oxidation (Jansson, 1980; Jansson et al. 1982).

\section{Diet and skeletal muscle metabolism during exercise}

Few studies have made the necessary measurements to determine accurately the effects of diet manipulation on skeletal-muscle substrate metabolism and, hence, to speculate on the mechanisms that induce the changes (Jansson, 
1980; Putman et al. 1993). The remainder of the present paper will examine a recent study that attempted to provide a more comprehensive view of diet-induced changes in muscle metabolism in exercising human subjects. Putman et al. (1993) investigated the effects of two extreme diets on substrate and metabolite turnover across the working leg muscles, and muscle fuel and metabolite contents at rest and during exercise at $75 \% \quad V_{\mathrm{O}_{2} \max }$. The well-trained subjects began the experiment by performing glycogendepleting exercise and then consumed a low-CHO-high-fat diet (\% total energy; $3 \mathrm{CHO}, 51$ fat, 46 protein; LCD) for $3 \mathrm{~d}$. After 1 week they repeated the procedure but consumed a high-CHO-low-fat diet (\% total energy; 86 CHO, 4 fat, 10 protein; HCD) for $3 \mathrm{~d}$. The exercise and LCD regimen left the subjects with much lower resting glycogen stores than following the HCD regimen (185 v. $655 \mathrm{mmol} / \mathrm{g}$ dry weight). The subjects cycled to exhaustion in $48 \mathrm{~min}$ in the LCD condition and cycled for the same length of time in the HCD condition. There were no differences in $V_{\mathrm{O}_{2}}$ during the trials. During the steady-state portion of the HCD ride the RER was 0.90, which indicated that $67 \%$ of the oxidized fuel came from CHO and $33 \%$ from fat. In the LCD condition the RER was 0.80 , indicating a full reversal with fat providing $67 \%$ of the oxidized substrate and $\mathrm{CHO}$ only $33 \%$. Arterial blood glucose levels were maintained at approximately $5 \mathrm{mmol} / 1$ throughout the HCD while they decreased to 3.7 and $2.5 \mathrm{mmol} / 1$ at $30 \mathrm{~min}$ and exhaustion in the LCD condition (Fig. 5). Arterial blood lactate levels were 2-fold higher and glycerol levels were 2-3-fold lower throughout exercise in the HCD condition. Arterial NEFA levels were 0.57 and $1.26 \mathrm{mmol} / \mathrm{l}$ at rest just before cycling in the HCD and LCD conditions and decreased in both trials at the onset of exercise, but remained higher in the LCD condition throughout exercise (Fig. 6). Total leg glucose uptake was 2-fold higher during exercise in the LCD condition. Total leg NEFA uptake was 4-fold higher and glycerol release 5-6-fold higher in the LCD condition during exercise. The increased glycerol release implied greater

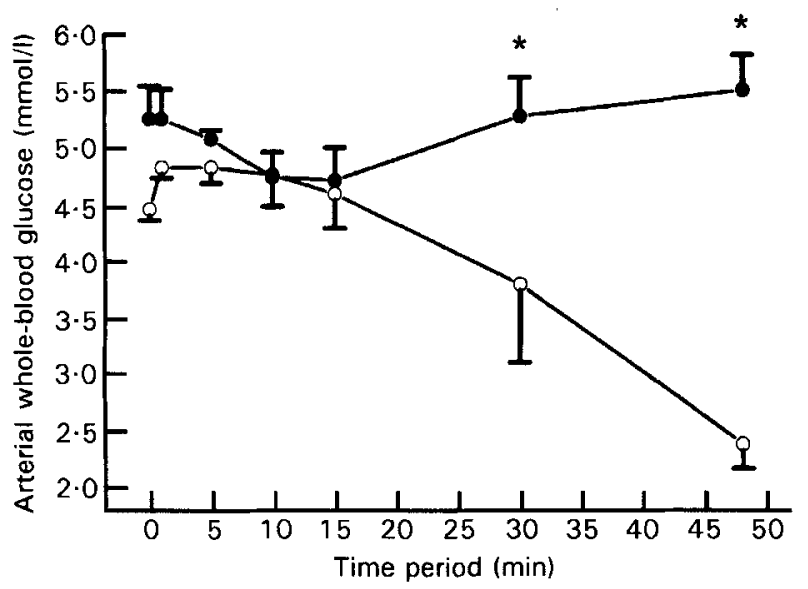

Fig. 5. Arterial concentration of glucose at $75 \%$ of maximum oxygen uptake after $3 \mathrm{~d}$ on a low-carbohydrate $(\mathrm{CHO})$ diet $(\mathrm{O})$ compared with a high-CHO diet $(\Theta)$. Values are means with their standard errors represented by vertical bars. Mean values were significantly different from those for matched time points in low-CHO condition: ${ }^{*} P<0.05$. (Data from Putman et al. 1993.)

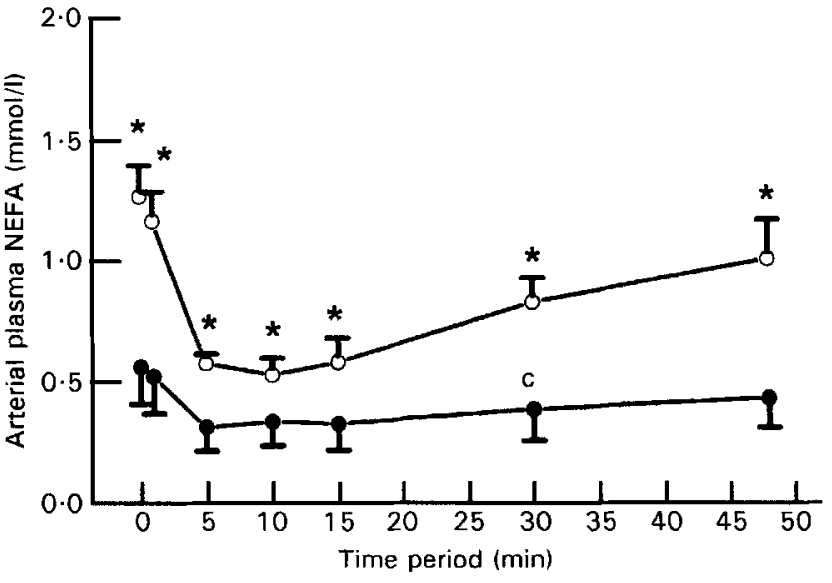

Fig. 6. Arterial concentration of plasma non-esterified fatty acids (NEFA) at $75 \%$ of maximum oxygen uptake after $3 \mathrm{~d}$ on a lowcarbohydrate $(\mathrm{CHO})$ diet $(\mathrm{O})$ compared with a high- $\mathrm{CHO}$ diet $(0)$. Values are means with their standard errors represented by vertical bars. Mean values were significantly different from those for matched time points in high-CHO condition: ${ }^{\star} P<0.05$. (Data from Putman et al. 1993.)

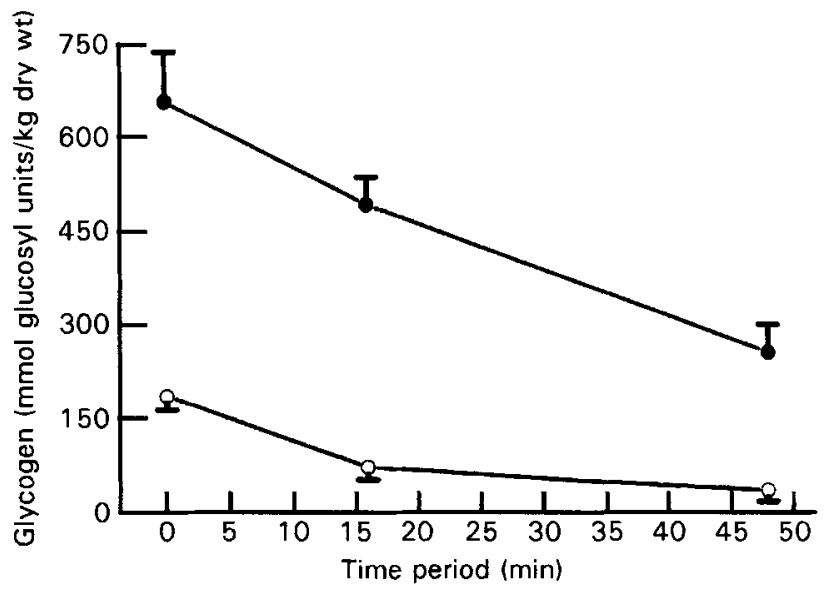

Fig. 7. Intramuscular glycogen content following $3 \mathrm{~d}$ on a lowcarbohydrate $(\mathrm{CHO})$ diet $(\mathrm{O})$ compared with a high-CHO diet $(\theta)$ during exercise at $75 \%$ maximum oxygen uptake. Values are means with their standard errors represented by vertical bars. (Data from Putman et al. 1993.)

$\mathrm{TAG}_{\mathrm{m}}$ lipolysis and presumably oxidation of $\mathrm{TAG}_{\mathrm{m}^{-}}$ derived NEFA in the LCD condition.

In the muscle, glycogen was used throughout exercise in the HCD condition but was essentially depleted by $15 \mathrm{~min}$ in the LCD (Fig. 7); consequently the energy derived from CHO during the period $15-48 \mathrm{~min}$ was derived almost entirely from blood glucose, leading to arterial hypoglycaemia. Muscle lactate and glucose-6-phosphate (G-6-P) contents were 2-3-fold lower and pyruvate was $30-50 \%$ lower throughout exercise in the LCD condition. Citrate levels were not different between diets at rest and during exercise.

At rest, the LCD resulted in 3 -fold increases in muscle acetyl-CoA (Fig. 8) and acetylcarnitine contents compared with the HCD. These changes were accompanied by a decrease in PDHa, presumably due to an increase in PDH 

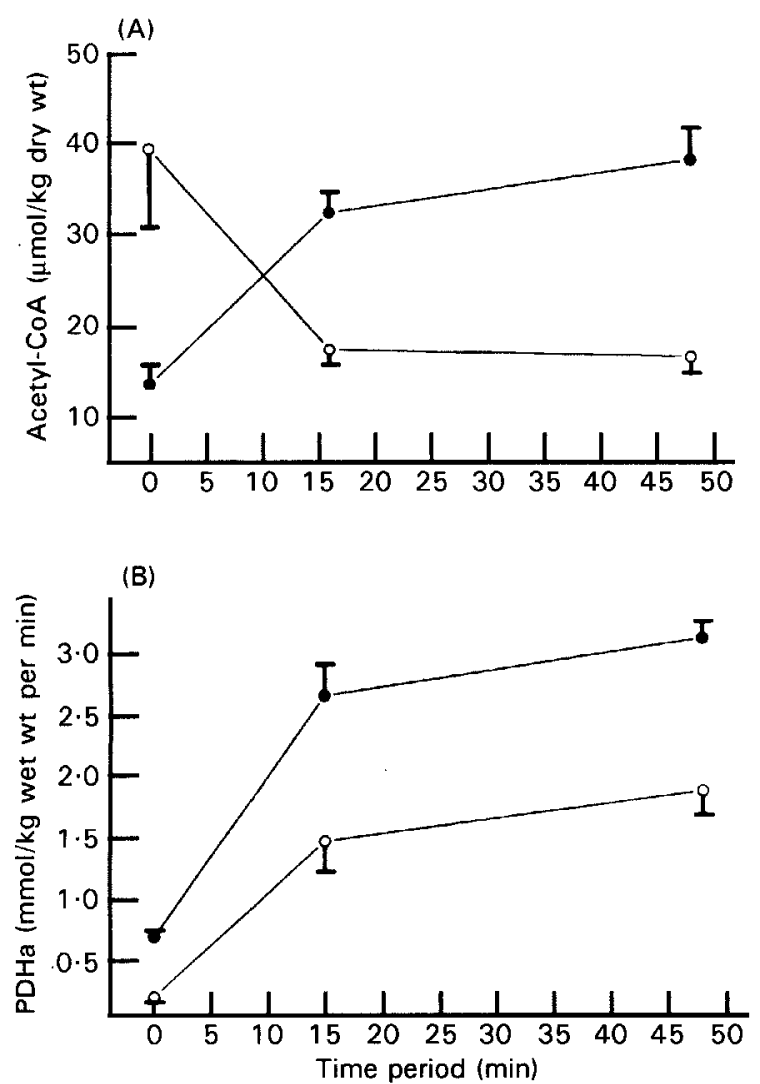

Fig. 8. (A) Intramuscular acetyl-CoA and (B) activity of pyruvate dehydrogenase in its active form (PDHa) following $3 \mathrm{~d}$ on a lowcarbohydrate $(\mathrm{CHO})$ diet $(\mathrm{O})$ compared with a high- $\mathrm{CHO}$ diet $(0)$ during exercise at $75 \%$ of maximum oxygen uptake. Values are means with their standard errors represented by vertical bars. (Data from Putman et al. 1993.)

kinase activity (Fuller \& Randle, 1984). During exercise at $75 \% V_{\mathrm{O}_{2} \max }$ in the HCD diet, muscle acetyl-CoA and acetylcarnitine increased 3-4-fold and remained elevated throughout exercise. Carnitine and free $\mathrm{CoA}$ (CoASH) decreased in a reciprocal manner. In contrast, acetyl-CoA and acetylcarnitine decreased from their elevated resting levels during the LCD condition. Surprisingly, CoASH did not increase in reciprocal manner, but also decreased. This suggested that about $50 \%$ of the CoASH was lost to another pool. At rest in the LCD condition, the production of acetyl units through increased $\beta$-oxidation of NEFA was greater than could be handled by the TCA cycle, resulting in the accumulation of acetyl-CoA. Excess acetyl-CoA was buffered by conversion to acetylcarnitine in order to maintain an adequate mitochondrial CoASH level, which is essential for many coenzyme-related processes. For example, with increased plasma NEFA uptake and $\mathrm{TAG}_{\mathrm{m}}$ utilization, one would predict an increase in mitochondrial fatty acyl-CoA synthesis, as most of the CoASH found in muscle is believed to be intramitochondrial. This has been confirmed, as rat skeletal muscle fatty acyl-CoA content increased by $46 \%$ after a 10 -week high-fat diet. This may help explain a proportional requirement for free $\mathrm{CoASH}$ (Chen et al. 1992).

During exercise at $75 \% V_{\mathrm{O}_{2} \max }$ in the $\mathrm{HCD}$ condition, acetyl-CoA production from $\beta$-oxidation and pyruvate production was greater than that required in the TCA cycle, leading to accumulations of acetyl-CoA and acetylcarnitine. The PDH complex was quickly converted to the active form (PDHa), presumably by increases in $\mathrm{Ca}^{2+}$ acting on PDH phosphatase (EC 3.1.3.43), and increases in pyruvate and decreases in the energy state of the cell deactivating PDH kinase (Fig. 8). Changes in the mitochondrial redox state may also play a role, but the large increase in acetyl-CoA : $\mathrm{CoASH}$, which should activate PDH kinase and prevent conversion to $\mathrm{PDHa}$, is clearly overridden during exercise. In the LCD condition, acetyl-CoA production from $\beta$-oxidation was not adequate to supply the increased flux through the TCA cycle. At the same time, conversion to PDHa was slower and PDH flux was limited by pyruvate availability leading to depletion of the acetyl-CoA and acetylcarnitine pools. The lower acetyl-CoA : CoASH during exercise in LCD should have deactivated PDH kinase and increased conversion of the complex to PDHa. However, the lower pyruvate may have reduced the inhibition PDH kinase or the less-active form of PDH may have been resistant to dephosphorylation (and, therefore, slower to activate). This has been attributed to multi-site phosphorylation similar to that observed in other situations with severe CHO deficiency (Sale \& Randle, 1982).

Measurements of acetyl-CoA, citrate, PDHa and G-6-P in the high-CHO and high-fat conditions of this study permit comparisons with the glucose-fatty acid cycle or the classic explanation for the regulation between fat and $\mathrm{CHO}$ metabolism. Randle et al. (1963) proposed that the presence of high NEFA levels in the medium of perfused rat hearts and the medium of resting diaphragm muscle down-regulated CHO metabolism. Increased NEFA delivery to the muscles caused increased uptake and oxidation of fat which led to increases in mitochondrial acetyl-CoA and citrate levels. The high acetyl-CoA was believed to activate PDH kinase and decrease PDH activity, while the citrate moved into the cytoplasm and inhibited phosphofructokinase. The reduced flux through phosphofructokinase and PDH produced an accumulation of G-6-P, which decreased the rate of glucose phosphorylation and ultimately glucose uptake into muscle. In the Putman et al. (1993) study, at rest, the higher acetylCoA, lower PDHa and tendency for higher citrate in the LCD condition were consistent with decreased flux through glycolysis and PDH in the presence of higher NEFA levels. The unchanged resting G-6-P level in LCD was the only finding that was not consistent with the classic explanation. However, during exercise, the similar citrate and G-6-P accumulations in the two conditions, and the lower PDHa in the presence of reduced acetyl-CoA levels with the LCD argue against the classic proposal as the explanation for the decreased $\mathrm{CHO}$ metabolism. It seems likely that decreased flux through glycogen phosphorylase (EC 2.4.1.1) in the initial $15 \mathrm{~min}$ of exercise and the lack of substrate for glycogen phosphorylase during the period between 15 and 48 min explain the decreased reliance on CHO in the LCD condition.

A confounding factor in the Putman et al. (1993) study was the very low pre-exercise glycogen content in the LCD condition. This makes it difficult to conclude whether the differences in the metabolic responses to exercise between the diets were due to lack of $\mathrm{CHO}$ availability, resulting in a greater reliance on fat, or to adaptations to the low-CHO 
high-fat diet per se. It could be argued that, due to the short exposure to the low-CHO high-fat diet $(3 \mathrm{~d})$, most of the metabolic changes during exercise were the result of the lack of CHO. In addition, the LCD in this study contained a high protein content (approximately $46 \%$ total energy), which could alter the changes compared with a LCD which maintained protein intake at normal levels (approximately $20 \%$ total energy), and had higher fat intake (Phinney et al. 1982). It therefore seems reasonable to recommend that studies of this type should be repeated without the pre-diet glycogen-depleting exercise, in the hope of maintaining normal glycogen levels in both diets, and that exposure to the diets also be increased to at least $7 \mathrm{~d}$, while controlling for protein content.

\section{Summary}

The relationship between dietary intake and skeletalmuscle exercise metabolism is central to the interests of exercise physiologists. This area has been examined experimentally for over 100 years. Classic studies with male subjects demonstrated the importance of dietary $\mathrm{CHO}$ in maximizing muscle and liver glycogen stores in an attempt to optimize exercise performance. $\mathrm{CHO}$ becomes the predominant fuel for exercise at power outputs above $50-60 \% \quad V_{\mathrm{O}_{2} \max }$ and its availability limits prolonged aerobic exercise at intensities corresponding to $65-85 \%$ $V_{\mathrm{O}_{2} \max }$. Recent information suggests that female subjects are less able to maximize muscle glycogen stores through dietary means.

Contemporary studies have documented in more detail the greater reliance on CHO metabolism following a highCHO-low-fat and -protein diet and the greater reliance on fat metabolism following a low-CHO-high-fat and protein diet. More emphasis on documenting key enzymic changes in the energy-producing pathways and transport proteins has appeared. However, very little is known regarding the mechanisms that induce these changes over the short or long term in human skeletal muscle. For example, the central role of PDH activity in the selection of intramuscular fuel during exercise and the role of carnitine palmitoyltransferase 1 in the entry of NEFA into the mitochondria, and the effects of diet on these enzymes has received little attention to date.

Many research studies have examined extreme diet variations (\% total energy; $>85 \% \mathrm{CHO} v .<5-10 \% \mathrm{CHO}$ ) for short periods of time in an attempt to maximize dietinduced alterations and study the mechanisms responsible for the changes. However, future studies will need to examine less-severe diet alterations for longer periods of time that more accurately reflect what the normal population might experience, such as a diet containing (\% total energy) 60 fat, $20 \mathrm{CHO}, 20$ protein or the recently popular diet with (\% total energy) 30 fat, $40 \mathrm{CHO}, 30$ protein.

\section{References}

Asmussen E (1971) Muscle metabolism during exercise in man: A historical survey. In Advances in Experimental Medicine and Biology, vol. 11, Muscle Metabolism During Exercise, pp. 1-12
[B Pernow and B Saltin, editors]. New York and London: Plenum Press.

Bergstrom J, Hermansen L, Hultman E \& Saltin B (1967) Diet, muscle glycogen and physical performance. Acta Physiologica Scandinavica 71, 140-150.

Bergstrom J \& Hultman E (1966) Muscle glycogen synthesis after exercise: An enhancing factor localized to the muscle cells in man. Nature 210, 309-310.

Bergstrom J \& Hultman E (1967) A study of the glycogen metabolism during exercise in man. Scandinavian Journal of Clinical Laboratory Investigation 19, 218-228.

Bryson JM, Cooney GJ, Wensley VR, Phuyal JL, Hew M, Denyer GS \& Caterson I (1995) High-fat feeding alters the response of rat $\mathrm{PDH}$ complex to acute changes in glucose and insulin. American Journal of Physiology 268, E752-E757.

Chen M-T, Kaufman LN, Spennetta T \& Shrago E (1992) Effects of high fat-feeding to rats on the interrelationship of body weight, plasma insulin, and fatty acyl-coenzyme A esters in liver and skeletal muscle. Metabolism 41, 564-569.

Coggan AR \& Mendenhall MA (1992) Effect of diet on substrate metabolism during exercise. In Perspectives in Exercise Science and Sports Medicine, vol. 5, Energy Metabolism in Exercise and Sport, pp. 435-471 [DR Lamb and CV Gisolfi, editors]. Dubuque, IA: Brown and Benchmark Inc.

Conlee RK, Hammer RL, Winder WW, Bracken ML, Nelson AG \& Barnett DW (1990) Glycogen repletion and exercise endurance in rats adapted to a high fat diet. Metabolism 39, 289-294.

Coyle EF (1997) Fuels for sport performance. In Perspectives in Exercise Science and Sports Medicine, vol. 10, Optimizing Sport Performance, pp. 125-137 [DR Lamb and R Murray, editors]. Carmel, IN: Cooper Publishing Group.

Cutler DL, Gray CG, Park SW, Hickman MG, Bell JM \& Kolterman OG (1995) Low-carbohydrate diet alters intracellular glucose metabolism but not overall glucose disposal in exercise-trained subjects. Metabolism 44, 1264-1270.

Frayn KN \& Maycock PF (1980) Skeletal muscle triacylglycerol in the rat: methods for sampling and measurement and studies of biological variability. Journal of Lipid Research 21, 139144.

Froberg SO, Carlson LA \& Ekelund LG (1971) Local lipid stores and exercise. In Advances in Experimental Medicine and Biology, vol. 11, Muscle Metabolism During Exercise, pp. 307313 [B Pernow and B Saltin, editors]. New York and London: Plenum Press.

Fryer LGD, Orfali KA, Holness MJ, Saggerson ED \& Sugden MC (1995) The long-term regulation of skeletal muscle pyruvate dehydrogenase kinase by dietary lipid is dependent on fatty acid composition. European Journal of Biochemistry 229, 741-748.

Fuller SJ \& Randle PJ (1984). Reversible phosphorylation of pyruvate dehydrogenase in rat skeletal-muscle mitochondria: effects of starvation and diabetes. Biochemical Journal 219, 635-636.

Havel RJ, Pernow B \& Jones NL (1967) Uptake and release of free fatty acids and other metabolites in the legs of exercising men. Journal of Applied Physiology 23, 90-99.

Helge JW \& Kiens B (1997) Muscle enzyme activity in humans: role of substrate availability and training. American Journal of Physialogy 273, R1620-R1624.

Helge JW, Richter EA \& Kiens B (1996) Interaction of training and diet on metabolism and endurance during exercise in man. Journal of Physiology 492, 293-306.

Holloszy JO \& Coyle EF (1984) Adaptation of skeletal muscle to endurance exercise and their metabolic consequences. Journal of Applied Physiology 56, 831-838.

Hultman E (1967) Studies on muscle metabolism of glycogen and active phosphate in man with special reference to exercise and 
diet. Scandinavian Journal of Clinical Laboratory Investigation 94, Suppl., 1-63.

Hultman E \& Bergstrom J (1967) Muscle glycogen synthesis in relation to diet studied in normal subjects. Acta Medica Scandinavica 182, 109-117.

Hultman E \& Nilsson LH (1971) Liver glycogen in man: Effect of different diets and muscular exercise. In Advances in Experimental Medicine and Biology, vol. 11, Muscle Metabolism During Exercise, pp. 143-151 [B Pernow and B Saltin, editors]. New York and London: Plenum Press.

Hultman E \& Spriet LL (1988) Dietary intake prior to and during exercise. In Exercise, Nutrition and Energy Metabolism, pp. 132-149 [ES Horton and RL Terjung, editors]. Toronto: Collier Macmillan Canada Inc.

Jansson E (1980) Diet and muscle metabolism in man with reference to fat and carbohydrate utilization and its regulation. Acta Physiologica Scandinavica 487, Suppl., 1-24.

Jansson E, Hjemdahl P \& Kaijser L (1982) Diet induced changes in sympatho-adrenal activity during submaximal exercise in relation to substrate utilization in man. Acta Physiologica Scandinavica 114, 171-178.

Johannessen A, Hagen C \& Galbo H (1982) Prolactin, growth hormone, thyrotropin, 3,5,3'-triiodothyronine, and thyroxine responses to exercise after fat- and carbohydrate-enriched diet. Journal of Clinical Endocrinology and Metabolism 52, 56-61.

Karlsson J \& Saltin B (1971) Diet, muscle glycogen, and endurance performance. Journal of Applied Physiology 31, 203-206.

Kiens B, Essen-Gustavsson B, Gad P \& Lithell H (1987) Lipoprotein lipase activity and intramuscular triglyceride stores after long-term high-fat and high-carbohydrate diet in physically trained men. Clinical Physiology 7, 1-9.

Lapachet RAB, Miller WC \& Arnall DA (1996) Body fat and exercise endurance in trained rats adapted to a high-fat and/or high-carbohydrate diet. Journal of Applied Physiology 80, $1173-1179$.

Liu S, Baracos VE, Quinney HA \& Clandinin T (1996) Dietary fat modifies exercise-dependent glucose transport in skeletal muscle. Journal of Applied Physiology 80, 1219-1224.

Miller WC, Bryce GR \& Conlee RK (1984) Adaptations to a highfat diet that increase exercise endurance in male rats. Journal of Applied Physiology 56, 78-83.

Nemeth PM, Rosser BWC, Choksi RM, Norris BJ \& Baker KM (1992) Metabolic response to a high-fat diet in neonatal and adult rat muscle. American Journal of Physiology 262, C282C286.

Orfali KA, Fryer LGD, Holness MJ \& Sugden MC (1993) Longterm regulation of pyruvate dehydrogenase kinase by high-fat feeding: Experiments in vivo and in cultured cardiomyocytes. FEBS Letters 336, 501-505.

Oscai LB \& Esser K (1996) Regulation of muscle triglyceride metabolism in exercise. In Biochemistry of Exercise, vol. 9, pp. 105-115 [RJ Maughan and SM Shirreffs, editors]. Leeds: Human Kinetics Publishers Inc.
Phinney SD, Bistria BR, Evans WJ, Gervino E \& Blackburn GL (1982) The human metabolic response to chronic ketosis without caloric restriction: preservation of submaximal exercise capability with reduced carbohydrate oxidation. Metabolism 32, 769-776.

Putman CT, Spriet LL, Hultman E, Lindinger MI, Lands LC, McKelvie RS, Cederblad G, Jones NL \& Heigenhauser GJF (1993) Pyruvate dehydrogenase activity and acetyl group accumulation during exercise after different diets. American Journal of Physiology 265, E752-E760.

Randle PJ, Garland PB, Hales CN \& Newsholme EA (1963) The glucose-fatty acid cycle: its role in insulin sensitivity and the metabolic disturbances of diabetes mellitus. Lancet i, 785-789.

Romijn JA, Coyle EF, Sidossis LS, Gastaldelli A, Horowitz JF, Endert E \& Wolfe RR (1993) Regulation of endogenous fat and carbohydrate metabolism in relation to exercise intensity and duration. American Journal of Physiology 265, E380-E391.

Sale GJ \& Randle PJ (1982) Occupancy of phosphorylation sites in pyruvate dehydrogenase phosphate complex in rat heart in vivo: Relation to proportion of inactive complex and rate of re-activation by phosphatase. Biochemical Journal 206, 221229.

Saltin B \& Karlsson J (1971) Muscle glycogen utilization during work of different intensities. In Advances in Experimental Medicine and Biology, vol. 11, Muscle Metabolism During Exercise, pp. 289-299 [B Pernow and B Saltin, editors]. New York and London: Plenum Press.

Sherman WM, Costill DL, Fink WJ \& Miller JM (1991) Effect of exercise-diet manipulation on muscle glycogen and its subsequent utilization during performance. International Journal of Sports Medicine 2, 114-118.

Simi B, Sempore B, Mayet M-H \& Favier RJ (1991) Additive effects of training and high-fat diet on energy metabolism during exercise. Journal of Applied Physiology 71, 197-203.

Tarnopolsky M, Atkinson SA, Phillips SM \& MacDougall JD (1995) Carbohydrate loading and metabolism during exercise in men and women. Journal of Applied Physiology 75, 2134-2141.

Taylor CR, Hoppeler H, Kennedy C, Valenski T, Roberts TJ \& Weyand P (1994) High fat diet improves aerobic performance by building mitochondria. The Physiologist 37, A84 Abstr.

Thomas CD, Peters JC, Reed GW, Abumrad NN, Sun M \& Hill JO (1992) Nutrient balance and energy expenditure during ad libitum feeding of high-fat and high-carbohydrate diets in humans. American Journal of Clinical Nutrition 55, 934-952.

Walker JL, Heigenhauser GJF, Hultman E \& Spriet LL (1996) Dietary carbohydrate, muscle glycogen content and endurance performance in well-trained female athletes. The Physiologist 39, A10 Abstr.

Wending PS, Peters SJ, Heigenhauser GJF \& Spriet LL (1996) Variability of triacylglycerol content in human skeletal muscle biopsy samples. Journal of Applied Physiology 81, 1150-1155.

Zierath JR, Houseknecht KL, Gnudi L \& Kahn BB (1997) Highfat feeding impairs insulin-stimulated GLUT4 recruitment via an early insulin-signalling defect. Diabetes 36, 215-223. 